\title{
Electrodeposition of Poly(sodium 4-Styrenesulfonate)-Silver Nanocomposites for Electrochemical Detection of $\mathrm{H}_{2} \mathrm{O}_{2}$
}

\author{
Qingbin Guo ${ }^{*}$, Meixia Li \\ Hebei University of Engineering, Handan, Hebei, 056038, P.R. China \\ *E-mail: qingbinguo_hun@yeah.net
}

doi: $10.20964 / 2016.09 .14$

Received: 27 May 2016 / Accepted: 13 July 2016 / Published: 7 August 2016

\begin{abstract}
A polystyrene sulphonic acid-silver nanocomposite (PSS-Ag NPs) using $\mathrm{AgNO}_{3}$-PSS solution as precursor was successfully deposited on the glassy carbon electrode (GCE) via electrodeposition. The prepared PSS-Ag NPs/GCE was then applied as active electrode material of non-enzymatic electrochemical sensors for $\mathrm{H}_{2} \mathrm{O}_{2}$ detection. The performance of PSS-Ag NPs/GCE for electrocatalytic reduction of $\mathrm{H}_{2} \mathrm{O}_{2}$ was better than that of $\mathrm{Ag}$ NPS/GCE and PSS/GCE electrode. The linear response ranging of the sensor with PSS-Ag NPs modified electrode was from $1.5 \mu \mathrm{M}$ to $2.0 \mathrm{mM}$. And the detection limit was $0.7 \mu \mathrm{M}(S / N=3)$. Owing to the outstanding electrocatalytic activity and rapidly electron transport property of PSS-Ag NPs composite, the non-enzymatic $\mathrm{H}_{2} \mathrm{O}_{2}$ sensor constructed with PSS-Ag NPs/GCE was highly stable and sensitive.
\end{abstract}

Keywords: Polystyrene sulphonic acid; Silver nanoparticles; $\mathrm{H}_{2} \mathrm{O}_{2}$; Electrodeposition; Sensor

\section{FULL TEXT}

(C) 2016 The Authors. Published by ESG (www.electrochemsci.org). This article is an open access article distributed under the terms and conditions of the Creative Commons Attribution license (http://creativecommons.org/licenses/by/4.0/). 